WORKING PAPER NO. 96-14

\title{
SAFETY IN NUMBERS? GEOGRAPHIC DIVERSIFICATION AND BANK INSOLVENCY RISK
}

\author{
Joseph P. Hughes \\ Rutgers University \\ William Lang \\ Office of the Comptroller of the Currency \\ Loretta J. Mester \\ Federal Reserve Bank of Philadelphia \\ and \\ The Wharton School, University of Pennsylvania \\ Choon-Geol Moon \\ Hanyang University
}

May 1996

The authors would like to thank William C. Hunter, whose comments on a previous paper inspired this investigation.

The views expressed in this paper do not necessarily represent those of the Federal Reserve Bank of Philadelphia or of the Federal Reserve System or of the Office of the Comptroller of the Currency. 


\title{
SAFETY IN NUMBERS? GEOGRAPHIC DIVERSIFICATION AND BANK INSOLVENCY RISK
}

\begin{abstract}
The Riegle-Neal Interstate Banking and Branching Efficiency Act, passed in September 1994 and effective June 1, 1997, will allow nationally chartered banks to branch across state lines. This act will remove impediments to interstate expansion and permit the consolidation of existing interstate networks.

What will be the impact of this legislation on bank performance and bank safety? Removing impediments to geographic expansion should improve the risk-return tradeoff faced by most banks. However, this paper argues that economic theory does not tell us whether an improvement in the riskreturn tradeoff will lead to a reduction in the volatility of bank returns or in the probability of insolvency. We investigate the role of geographic diversification on bank performance and safety using bank holding company data. We find that an increase in the number of branches lowers insolvency risk and increases efficiency for inefficient bank holding companies; an increase in the number of states in which a bank holding company operates increases insolvency risk but has an insignificant effect on efficiency. Branch expansion raises the risk of insolvency for efficient bank holding companies, while an increase in the number of states has an insignificant effect on insolvency risk.
\end{abstract}




\section{SAFETY IN NUMBERS? GEOGRAPHIC DIVERSIFICATION AND BANK INSOLVENCY RISK}

\section{Introduction}

In spite of considerable legal obstacles, banks in the United States have strived to cross state lines. Despite the apparent desire by banks to expand geographically, many studies of interstate banking have not found an inverse relationship between the volatility of bank returns and measures of geographic diversity. ${ }^{1}$ At first glance this might seem to contradict the simple intuition that geographic expansion will lead to a decrease in the riskiness of bank returns. This paper argues that an increase in the riskiness of bank returns as a result of geographical diversification is consistent with economic theory and is consistent with the notion that geographical diversification can improve bank efficiency.

Even if the volatility of bank returns rises as a result of geographic diversification, the probability of bank insolvency would fall if there were a sufficiently large increase in expected returns. However, economic theory alone cannot tell us whether there will be a rise or a fall in bank safety in response to improved opportunities to diversify. ${ }^{2}$

This theoretical indeterminacy emphasizes the need for empirically estimating bank responses to geographical diversification. This paper extends the empirical work in Hughes, Lang, Mester, and Moon (hereafter referred to as HLMM) (forthcoming) by studying the impact of geographical diversification on bank insolvency risk on a sample of 443 U.S. bank holding companies (BHCs) operating in 1994. As in that paper, we employ a model of production developed by HLMM (1995) that allows managers to trade return for reduced risk. The model accommodates non-neutral preferences toward risk while allowing for risk neutrality as a special case. This provides a test of the usual assumption of neutrality. Based on the profit function, the production system employs the Almost Ideal Demand System to obtain the functional forms for the profit and input share equations. In the case where managers are risk neutral or, equivalently, profit is maximized, the functional forms are identical to the standard translog profit system.

Using procedures developed by Hughes and Moon (1995), the estimated profit function, 
conditioned on equity capital, is used to obtain an expected rate of return on equity for each BHC in the sample. The standard error of the prediction proxies risk and a stochastic risk-return frontier is estimated to obtain a best-practice frontier. Various measures of efficiency, representing the distance of each bank from the best-practice, risk-return frontier, are then computed. ${ }^{3}$ Finally, the effects of geographic diversification on expected return, risk, efficiency, and the probability of insolvency are estimated.

The estimated effects of geographic diversification on return, risk, and safety depend on whether the BHC is inefficient or efficient. For inefficient BHCs, an increase in the number of branches in the BHC has a significant negative effect on risk without a statistically significant effect on expected return and a significant positive effect on the efficiency of inefficient BHCs. An increase in the number of states in which a BHC operates has a significant positive effect on risk, an insignificant effect on expected return, and an insignificant positive effect on efficiency. A proportionate increase in number of states and branches has a significant positive effect on expected return, a significant positive effect on risk (when BHC asset size is allowed to vary along with the number of states and branches), and a significant positive effect on efficiency. For efficient BHCs, only the number of branches has a significant effect on expected return or risk. An increase in the number of branches in the BHC has a significant negative effect on expected return and risk, moving the BHC downward along the efficient risk-return frontier. The number of states, asset size, and a proportionate increase in number of states and branches are insignificant. Thus, in contrast to inefficient BHCs, geographic expansiveness does not appear to be an advantage for efficient BHCs.

For both efficient and inefficient BHCs, an increase in number of branches is significantly related to a decrease in bank safety. The effect of an increase in the number of states is of opposite sign and is significant for inefficient BHCs. A proportionate increase in the number of branches and states, holding BHC asset size constant, has an insignificant effect on insolvency risk. When BHC size is allowed to vary, a proportionate increase in branches and states has a significant positive effect on insolvency risk for inefficient BHCs, reflecting the effect of an increase in BHC size. 


\section{Geographical Diversification and Managerial Risk Preferences}

The Riegle-Neal Interstate Banking and Branching Efficiency Act, passed in September 1994 and effective June 1, 1997, opens new avenues to interstate expansion and permits the consolidation of existing interstate networks. Reduced barriers to geographic expansion are expected to enhance opportunities for diversification and reduce the operating costs of existing interstate structures. Simple logic would seem to indicate that such changes will increase efficiency and create a safer banking system.

Enhancing the diversification of assets and liabilities allows banks to improve their risk-return tradeoff. In other words, at any given level of risk, return is improved or, equivalently, at any given rate of return, risk is reduced. However, while diversification lowers the risk of obtaining the bank's current level of returns, diversification also changes the marginal compensation for risk-taking. At the margin, the extra returns that can be obtained for an increase in risk, the marginal compensation for risk, will increase at any level of expected return. Equivalently, the price of risk is reduced.

How do risk-averse banks respond to a change in the marginal compensation for risk-taking? Does the diversifying bank's demand for risk increase or decrease? This depends on the magnitude of the substitution and wealth effects from a lowering of the price of risk. The substitution effect implies that the bank takes on more risk in response to the lower price. The direction of the wealth effect can be positive or negative depending on the underlying risk preferences of the bank. Thus, the sum of the two effects depends on the bank's preferences for risk and return. A risk-averse bank that diversifies reduces its price of risk and, in response, may increase its risk-taking or reduce it. Hence, the bank that diversifies doesn't necessarily lower the volatility of its returns.

The effects on the risk-return frontier of an increase in geographic diversification should depend on whether banks are efficient or inefficient. Efficient BHCs operate on the envelope of the risk-return frontiers of all individual BHCs (what we call the "envelope frontier"), while inefficient BHCs operate on frontiers inside the envelope (see Hughes and Moon, 1995). 
An inefficient BHC that improves its diversification should be able to reduce risk at any given level of return or, equivalently, to increase return at any given level of risk, except at the risk-free return on government securities. In other words, enhanced diversification shifts the risk-return frontier upward at all positive levels of risk. As illustrated in Figure 1, increased geographic diversification rotates the frontier upward from its intersection with the vertical axis (the risk-free return), shifting the frontier upward and changing its slope at any given level of risk. ${ }^{4}$

How do inefficient BHCs that diversify respond to the lower price of risk? One possible outcome is a movement from the original point A to point D. This case generates the "intuition" that improved diversification will lead to lower risk and higher return. However, a new tangency at point $\mathrm{D}^{\prime}$ cannot be ruled out.

The same analysis holds for a risk-neutral bank, which maximizes return. At the maximum return, the price of risk is zero, since the indifference curves are horizontal. Although diversification necessarily increases the maximum return, it is not clear, a priori, how it affects the level of risk where return is maximized. This can be seen in Figure 1 where the new maximum is at a higher level of risk.

What, then, constitutes evidence that greater geographic extensiveness leads to greater diversification for inefficient banks? If diversification does not necessarily reduce risk, it must increase return and improve the efficiency of inefficient BHCs.

The impact of geographical diversification on efficient BHCs differs from the inefficient case. The BHCs operating on the envelope frontier have efficiently exploited their chosen strategies of diversification. Hence, a variation in one of those strategies, such as geographic expansion, may have no effect on expected return and risk or it may move the BHC along the envelope frontier. In the latter case, one would expect the geographically diverse BHCs to be located in a specific region of the envelope, while, in the former case, they should be scattered over the envelope. ${ }^{5}$

While bank regulation aims at improving bank efficiency and profitability, bank regulators are particularly concerned with the impact of policy changes on bank safety. Since risk measured relative to 
return is a component of a bank's risk of insolvency, enhanced diversification also implies that the risk of insolvency is reduced at any given level of return. Moreover, even if the volatility of returns rises as a result of improved opportunities for diversification, the risk of insolvency could still fall if the positive impact on bank returns is sufficiently large. In other words, the conditions under which insolvency risk would rise in response to increased diversification are stronger than the conditions that lead to an increase in the riskiness of bank returns. Theoretically it is still feasible for a bank to make choices that increase insolvency risk in response to improved opportunities to diversify.

One measure of the risk of insolvency is the inverse z-score, i.e., the standard deviation of profit divided by the sum of bank capital and expected profit, which equals the standard deviation of return on equity divided by $(1+$ expected return on equity). We use this measure of (inverse) bank safety to show the effect of improved diversification on the safety of inefficient BHCs (Figure 2), where return is measured as return on equity and risk is measured as the standard deviation of return on equity.

The iso-inverse z-score contours, which show all risk-return combinations that have the same inverse z-score, are linear, and contours to the right imply higher inverse z-scores (higher insolvency risk). ${ }^{6}$ An inefficient $\mathrm{BHC}$ operating at point A that diversifies geographically is able to choose from a range of more efficient production plans on the higher frontier. Points on the new frontier to the left of point B are safer than the one at point A. The BHC could, of course, choose a point to the right of B. Hence, there is no a priori prediction.

The effect on safety of a change in the diversification strategy of an efficient BHC depends on how the change shifts the BHC's position on the envelope. From Figure 2, it is clear that a movement along the frontier toward higher return and higher risk must necessarily increase the inverse z-score and, thus, reduce safety. ${ }^{7}$

\section{Modeling Risky Production and Managerial Risk Preferences}

We characterize banking technology in terms of financial intermediation. Banks employ labor, 
physical capital, and various funding sources, including equity (financial) capital, to produce investments in financial outputs, principally loans and securities. Equity capital is not only a source of loanable funds, but it also serves as a cushion against loan losses that threaten the bank's solvency. Denoting the output vector by $\mathbf{y}$, the input vector by $\mathbf{x}$, and equity capital by $\mathrm{k}$, the bank's production technology is represented by the transformation function $\mathrm{T}(\mathbf{y}, \mathbf{x}, \mathrm{k})=0$, where $\frac{\partial T}{\partial y_{i}}>0$ and $\frac{\partial T}{\partial x_{j}}<0$.

Any production plan $(\mathbf{y}, \mathbf{x}, \mathrm{k})$ involves a variety of risks. The quality of the assets and the intensity of resources devoted to credit analysis and loan monitoring shape the credit risk. The durations of assets and liabilities determine the interest rate risk. The duration of the liabilities affects the liquidity risk. The level of financial capital influences the risk of insolvency.

Controlling risks is costly. Additional resources devoted to credit analysis and loan monitoring reduce credit risk and increase return. The risk-neutral bank invests in these additional resources until the net return is maximized. The risk-averse bank is willing to invest even more intensively in these inputs to further reduce credit risk. In doing so, though, it sacrifices return for reduced risk. By the standard of risk neutrality, it has "overemployed" these inputs.

Similarly, the risk-averse bank might employ more expensive but less volatile funding sources to reduce liquidity risk. It might hold a higher proportion of its assets in securities to reduce overall credit risk, even at the expense of reduced profits. Thus, the bank managers' most preferred production plan does not necessarily maximize profit.

\section{II.A. Managerial Utility}

The influence of the bank managers' preferences for risk on the organization of production can be represented by a managerial utility function that includes profit, $\pi$, and the production plan, $(\mathbf{y}, \mathbf{x}, \mathrm{k})$. The inclusion of the production plan in the utility function accounts for risk and potentially non-neutral risk preferences. Managers who are risk-neutral maximize expected profit. Managers who are risk-averse accept lower profit for reduced risk. Hence, the managers' most preferred production plan maximizes 
utility but not necessarily profit.

Hughes and Moon (1995) argue that the inclusion of the production plan in the utility function, rather than expected profit and risk, provides a more general representation of risk and risk preferences. Under certain conditions the more general representation is equivalent to utility expressed in terms of expected profit and risk. Stochastic market conditions interact in complex ways with the feasible production plans to determine the risk inherent in production. Given these stochastic market conditions, any technologically feasible production plan entails an expected return and risk.

The realization of stochastic market conditions, represented by the state variable s, and the production plan, $(\mathbf{y}, \mathbf{x}, \mathrm{k})$, imply a realization of profit $\pi=\mathrm{g}(\mathbf{y}, \mathbf{x}, \mathrm{k}, \mathrm{s})$. Employing the probability distribution of s, a conditional probability distribution for realized profit, $\mathrm{f}(\pi ; \mathbf{y}, \mathbf{x}, \mathrm{k})$, can be obtained.

Hence, the production plan $(\mathrm{y}, \mathrm{x}, \mathrm{k})$ implies an expected profit, $E(\pi ; \boldsymbol{y}, \boldsymbol{x}, k)=\int_{-\infty}^{\infty}[f(\pi ; \boldsymbol{y}, \boldsymbol{x}, k) \pi] d \pi$ and a level of risk measured by the standard deviation $S(\pi ; \mathbf{y}, \mathbf{x}, \mathrm{k})$.

The managerial utility function defined over profit and the production plan ranks distributions of profit. If managers are risk-neutral, they rank plans only by the first moment of the distribution.

However, if they are not risk-neutral, higher moments of the distribution will matter in the ranking. For certain probability distributions and utility functions, utility can be characterized solely in terms of the first and second moments. Thus, utility defined over profit and the production plan subsumes these cases and allows greater generality.

To account for the important details of bank production, other arguments are also included in the utility function: $\mathrm{U}(\pi, \mathbf{y}, \mathbf{x}, \mathrm{k}, \mathbf{p}, \mathrm{r}, \mathrm{n})$, where $\mathbf{p}$ denotes the prices or interest rates earned by the outputs, $\mathrm{r}$ is the risk-free rate of return, and $\mathrm{n}$ is nonperforming assets. The prices of assets, relative to the risk-free rate of return, indicate the risk premium on assets, an ex ante measure of asset quality. The level of nonperforming loans is a gauge of ex post asset quality.

\section{II.B. The Most Preferred Production Plan}


The managers' most preferred production plan is the one out of all feasible plans that maximizes managerial utility:

$$
\begin{gathered}
\max _{\pi, \boldsymbol{x}} U(\pi, \boldsymbol{x} ; \boldsymbol{y}, \boldsymbol{p}, r, n, k) \\
\text { s.t. } \boldsymbol{p} \cdot \boldsymbol{y}+m-\boldsymbol{w} \cdot \boldsymbol{x}-p_{\pi} \pi=0 \\
T(\boldsymbol{x} ; \boldsymbol{y}, k) \leq 0
\end{gathered}
$$

where $\mathrm{m}$ denotes noninterest income, $\mathrm{p}_{\pi}$ is the price of a real dollar of after-tax accounting profit, $\pi$, in terms of nominal, before-tax dollars, $\mathrm{p}_{\pi}=1 /(1-\mathrm{t})$ where $\mathrm{t}$ is the marginal tax rate on profit and a real dollar is assumed equal to one nominal dollar. Hence, $\mathrm{p}_{\pi} \pi$ is nominal, before-tax accounting profit, which differs from nominal, before-tax economic profit, $\mathrm{p}_{\pi} \Pi$, by the required return on equity capital, $\mathrm{w}_{\mathrm{k}} \mathrm{k}$,

$$
\begin{aligned}
p_{\pi} \pi & =p_{\pi} \Pi+w_{k} k \\
& =\boldsymbol{p} \cdot y+m-\boldsymbol{w} \cdot x .
\end{aligned}
$$

The problem of maximizing managerial utility in (1)-(3) is conditioned on the level of equity capital so that maximizing utility with respect to accounting profit, $\pi$, is equivalent to maximizing it with respect to economic profit and with respect to profit divided by equity, the rate of return on equity. It is conditioned on the output vector so that the most preferred cost function can be computed (see HLMM, 1995 and forthcoming). For the purposes of deriving the expected return and risk of the production plan, the cost function can be ignored. Other studies have also used capital as a conditioning argument. Hancock $(1985,1986)$ conditioned the profit function on capital while Hughes and Mester (1993) and McAllister and McManus (1993) constructed cost functions that controlled for capitalization.

Denoting the price vector by $\mathbf{v}=\left(\mathbf{w}, \mathbf{p}, \mathrm{r}, \mathrm{p}_{\pi}\right)$, the most preferred production plan is defined by the utility-maximizing solution $\mathbf{x}(\mathbf{y}, \mathrm{n}, \mathbf{v}, \mathrm{m}, \mathrm{k})$ and $\pi(\mathbf{y}, \mathrm{n}, \mathbf{v}, \mathrm{m}, \mathrm{k})$. The profit function will account for any tradeoff of profit for reduced risk. Hence, it is sufficiently general to account for risk-averse as well as risk-neutral preferences. Dividing the profit function by equity capital transforms it into the rate of return on equity. 


\section{Deriving the Most Preferred Profit System from the Almost Ideal Demand System}

Characterizing the bank's management as maximizing utility subject to a technology constraint suggests that a functional form for the problem might be found in consumer theory. HLMM (1995) employ the Almost Ideal Demand System to obtain the most preferred profit system and show that in the case of risk-neutrality, it is identically equal to the standard translog profit function and share equations.

The Almost Ideal Demand System postulates a flexible functional form for the consumer's expenditure function and employs Shephard's lemma to obtain the expenditure-minimizing demand functions. Substituting the indirect utility function, obtained by inverting the expenditure function, into these demand functions, they are transformed into utility-maximizing demands, expressed as shares in expenditure.

\section{III.A. Adapting the Almost Ideal Demand System}

Following this procedure, HLMM (1995) adapt the Almost Ideal (AI) expenditure function to represent the generalized managerial preferences:

$$
\ln E(\cdot)=\ln P+U \cdot \beta_{0}\left(\prod_{i} y_{i}^{\beta_{i}}\right)\left(\prod_{j} w_{j}^{\mathrm{V}_{j}}\right) p_{\pi}^{\mu} k^{\mathrm{k}},
$$

where

$$
\begin{aligned}
\ln P= & \alpha_{0}+\alpha_{p} \ln \tilde{p}+\sum_{i} \delta_{i} \ln y_{i}+\sum_{i} \omega_{j} \ln w_{j} \\
& +\eta_{\pi} \ln p_{\pi}+\tau \ln r+\vartheta \ln n+\rho \ln k+\frac{1}{2} \alpha_{p p}(\ln \tilde{p})^{2}+\frac{1}{2} \sum_{i} \sum_{j} \delta_{i j} \ln y_{i} \ln y_{j} \\
& +\frac{1}{2} \sum_{s} \sum_{t} \omega_{i j}^{*} \ln w_{s} \ln w_{t}+\frac{1}{2} \eta_{\pi \pi}\left(\ln p_{\pi}\right)^{2} \\
& +\frac{1}{2} \tau_{r r}(\ln r)^{2}+\frac{1}{2} \vartheta_{n n}(\ln n)^{2}+\frac{1}{2} \rho_{k k}(\ln k)^{2} \\
& +\sum_{j} \theta_{p j} \ln \tilde{p} \ln y_{j}+\sum_{s} \varphi_{p s} \ln \tilde{p} \ln w_{s}+\psi_{p \pi} \ln \tilde{p} \ln p_{\pi} \\
& +\psi_{p r} \ln \tilde{p} \ln r+\psi_{p n} \ln \tilde{p} \ln n+\psi_{p k} \ln \tilde{p} \ln k
\end{aligned}
$$




$$
\begin{aligned}
& +\sum_{j} \sum_{s} \gamma_{j s} \ln y_{j} \ln w_{s}+\sum_{j} \gamma_{j \pi} \ln y_{j} \ln p_{\pi}+\sum_{j} \gamma_{j r} \ln y_{j} \ln r \\
& +\sum_{j} \gamma_{j n} \ln y_{j} \ln n+\sum_{j} \gamma_{j k} 1 \operatorname{l}_{y_{j}} \ln k \\
& +\frac{1}{2} \sum_{s} \omega_{s \pi}^{*} \ln w_{s} \ln p_{\pi}+\frac{1}{2} \sum_{s} \omega_{\pi s}^{*} \ln p_{\pi} \ln w_{s} \\
& +\sum_{s} \omega_{s r} \ln w_{s} \ln r+\sum_{s} \omega_{s n} \ln w_{s} \ln n+\sum_{s} \omega_{s k} \ln w_{s} \ln k \\
& +\eta_{\pi r} \ln p_{\pi} \ln r+\eta_{\pi n} \ln p_{\pi} \ln n+\eta_{\pi k} \ln p_{\pi} \ln k \\
& +\tau_{r n} \ln r \ln n+\tau_{r k} \ln r \ln k+\vartheta_{n k} \ln n \ln k
\end{aligned}
$$

To reduce the number of parameters to be estimated, the individual output prices, $\mathbf{p}$, are replaced by their weighted average, $\tilde{p}=\sum_{i} p_{i}\left[\frac{y_{i}}{\sum_{j} y_{j}}\right]$.

Inverting the expenditure function yields the indirect managerial utility function,

$$
V(\cdot)=\frac{\ln (\boldsymbol{p} \cdot \boldsymbol{y}+m)-\ln P}{\beta_{0}\left(\prod_{i} y_{i}^{\beta_{i}}\right)\left(\prod_{j} w_{i}^{v_{j}}\right) p_{\pi}^{\mu} k^{\kappa}}
$$

Applying Shephard's lemma to the expenditure function and substituting the indirect managerial utility function into it yields the utility-maximizing profit and input demand equations, expressed as shares in expenditure, $\mathbf{p} \cdot \mathbf{y}+\mathrm{m}$, on profit, $\mathrm{p}_{\pi} \pi$, and the inputs, $\mathbf{w} \cdot \mathbf{x}$ :

$$
\begin{aligned}
& \frac{\partial \ln E}{\partial \ln w_{i}}=\frac{w_{i} x_{i}}{\boldsymbol{p} \cdot \boldsymbol{y}+m}=\frac{\partial \ln P}{\partial \ln w_{i}}+v_{i}[\ln (\boldsymbol{p} \cdot \boldsymbol{y}+m)-\ln P] \\
& =\omega_{i}+\sum_{s} \omega_{s i} \ln w_{s}+\varphi_{p i} \ln \tilde{p}+\sum_{j} \gamma_{j i} \ln y_{j}+\omega_{\pi i} \ln p_{\pi} \\
& \quad+\omega_{i r} \ln r+\omega_{i n} \ln n+\omega_{i k} \ln k \\
& \quad+v_{i}[\ln (\boldsymbol{p} \cdot \boldsymbol{y}+m)-\ln P] \\
& \frac{\partial \ln E}{\partial \ln p_{\pi}}=\frac{p_{\pi} \pi}{\boldsymbol{p} \cdot \boldsymbol{y}+m}=\frac{\partial \ln P}{\partial \ln p_{\pi}}+\mu[\ln (\boldsymbol{p} \cdot \boldsymbol{y}+m)-\ln P] \\
& =\eta_{\pi}+\eta_{\pi \pi} \ln p_{\pi}+\psi_{p \pi} \ln \tilde{p}+\sum_{j} \gamma_{j \pi} \ln y_{j}+\sum_{s} \omega_{s \pi} \ln w_{s} \\
& \quad+\eta_{\pi r} \ln r+\eta_{\pi n} \ln n+\eta_{\pi k} \ln k \\
& \quad+\mu[\ln (\boldsymbol{p} \cdot \boldsymbol{y}+m)-\ln P] .
\end{aligned}
$$




\section{III.B. Deriving the Demand for Equity Capital}

Since the problem of maximizing constrained managerial utility was conditioned on the bank's capitalization, the most preferred level of equity capital can be obtained by adding a second stage to the

optimization. Hence, the conditional indirect utility function can be obtained by evaluating the Lagrangean function for the utility maximization problem at the optimum,

$$
\begin{aligned}
V(\boldsymbol{y}, n, \boldsymbol{v}, m, k) & \equiv U(\pi(\cdot), \boldsymbol{x}(\cdot) ; \boldsymbol{y}, \boldsymbol{p}, r, n, k) \\
& +\lambda(\cdot)\left[\boldsymbol{p} \cdot \boldsymbol{y}+m-\boldsymbol{w} \cdot \boldsymbol{x}(\cdot)-p_{\pi} \pi(\cdot)\right] \\
& +\gamma(\cdot)[T(x(\cdot) ; \boldsymbol{y}, k)] .
\end{aligned}
$$

and by maximizing (9) with respect to equity capital $\mathrm{k}$, the demand for equity capital follows from the resulting first-order condition,

$$
\begin{gathered}
\frac{\partial V(\cdot)}{\partial k}=\frac{\partial V(\cdot)}{\partial \ln k} \frac{\partial \ln k}{\partial k} \\
=-\frac{1}{k\left[\beta_{0}\left(\prod_{i} y_{i}^{\beta_{i}}\right)\left(\prod_{j} \omega_{j}^{v_{j}}\right) p_{\pi}^{\mu} k^{\kappa}\right]}\left[\frac{\partial \ln P}{\partial \ln k}+\kappa[\ln (\boldsymbol{p} \cdot \boldsymbol{y}+m)-\ln P]\right]=0 \\
\Rightarrow \rho+\rho_{k k} \ln k+\psi_{p k} \ln \tilde{p}+\sum_{j} \gamma_{j k} \ln y_{j}+\sum_{s} \omega_{s k} \ln w_{s}+\eta_{\pi k} \ln p_{\pi}+\tau_{r k} \ln r \\
+\vartheta_{n k} \ln n+\kappa[\ln (\boldsymbol{p} \cdot \boldsymbol{y}+m)-\ln P]=0 .
\end{gathered}
$$

\section{III.C. The Case of Risk Neutrality}

The standard translog profit (cost) function is embedded in the most preferred profit system. When the risk terms are omitted from the expression, $\ln \mathrm{P}$ becomes the standard translog cost function, conditioned on equity capital. Hence, the first term on the right-hand side of (8) resembles the translog 
input share equation in the case of risk neutrality. The second term is a normalized revenue effect. The right-hand side of (9) contains the full expression, ln P. These features of the most preferred profit system suggest that there are a set of parameter values implied by risk neutrality that reduce the most preferred system to the standard translog profit (cost) function.

If banks maximize profit or, equivalently, since the system is conditioned on equity capital, if they maximize the rate of return on equity, variations in the tax rate $\mathrm{p}_{\pi}$ will have no effect on the choice of before-tax profit. Additionally, the revenue and risk characteristics of production represented by the output price vector will not influence the bank's cost-minimizing production plan (conditioned on the output vector). Finally, a variation in $\mathrm{m}$ will have no marginal significance for the optimal input demands. Thus, profit maximization behavior implies a set of testable parameter restrictions derived in HLMM (1995).

\section{III.D. The Empirical Model}

Nonlinear two-stage least squares are employed to estimate the system of equations consisting of the profit share equation (8), the input share equations (7), and the first-order condition for capitalization (10). Adding up conditions and certain symmetry conditions are imposed on the estimation. Their details are discussed in HLMM (1995 and forthcoming).

\section{Deriving Risk, Return, and the Best-Practice Frontier}

Predicted profit, $\mathrm{p}_{\pi} \hat{t}$, from the estimated profit share equation (8), conditioned on the level of equity capital, is divided by capital to obtain an expected rate of return on equity, ER, for each BHC in the sample. The BHC's risk, RK, is measured by the standard error of the predicted profit, divided by capital, k. Both ER and RK are functions of $\left(\mathbf{y}, \mathrm{n}, \mathbf{w}, \mathbf{p}, \mathrm{r}, \mathrm{p}_{\pi}, \mathrm{m}, \mathrm{k}\right)$.

A best-practice risk-return frontier is computed by regressing expected return rescaled by its standard deviation, $\mathrm{ER}^{\prime}$, on a constant term, risk rescaled by its standard deviation, $\mathrm{RK}^{\prime}$, and on squared 
rescaled risk:

$$
E R_{i}^{\prime}=\Gamma_{0}+\Gamma_{1} R K_{i}^{\prime}+\Gamma_{2} R K_{i}^{\prime 2}+\varepsilon_{i}
$$

A composite error term, $\varepsilon_{\mathrm{i}}=v_{\mathrm{i}}+\mathrm{u}_{\mathrm{i}}$, is employed to distinguish inefficiency from statistical noise. The two-sided component, $v_{\mathrm{i}}$, is distributed $\mathrm{N}\left(0, \sigma_{\mathrm{v}}^{2}\right)$ and accounts for any unmeasured randomness in the data generation process of risk and return. The one-sided component, $\mathrm{u}_{\mathrm{i}}<0$ is distributed half normally, i.e., it is the absolute value of a variable distributed $\mathrm{N}\left(0, \sigma_{\mathrm{u}}^{2}\right)$, and gauges inefficiency, the failure to achieve the frontier return at a given level of risk.

The log-likelihood function of this frontier is

$$
\ln L=\frac{N}{2} \ln \frac{2}{\pi}-N \ln \sigma-\frac{1}{2 \sigma^{2}} \sum_{i=1}^{N} \varepsilon_{i}^{2}+\sum_{i=1}^{N} \ln \left[\Phi\left(-\frac{\varepsilon_{i} \lambda}{\sigma}\right)\right]
$$

where $\mathrm{N}$ is the number of BHCs, $\sigma^{2}=\sigma_{u}^{2}+\sigma_{v}^{2}, \lambda=\frac{\sigma_{u}}{\sigma_{v}}$, and $\Phi(\cdot)$ is the standard normal cumulative distribution function. We estimate this frontier using maximum-likelihood techniques.

\section{Measuring Efficiency}

BHCs that choose the production plan that maximizes return are, in the risk-neutral sense, allocatively efficient. BHCs that trade return for reduced risk are, by contrast, allocatively inefficient to the extent that they employ more expensive but less volatile funding sources to reduce liquidity risk and technically inefficient to the extent that they devote extra labor to analyze credit applications and monitor loans to reduce credit risk. To the extent that they choose a less risky, but less profitable mix of assets, they are allocatively inefficient. The risk-neutral concepts of allocative and technical efficiency do not allow for the possibility that the reduced risk may be achieved efficiently, that is, at the maximum return feasible at the given level of risk.

Although the failure to achieve allocative efficiency may represent agency problems, it may also reflect regulatory incentives. Since risk-taking by individual banks generates externalities affecting the payments system, regulators may induce risk-averse behavior in bank managers who would otherwise be 
neutral toward risk. Hence, when managers trade return for reduced risk, it is important to account for this tradeoff in measuring efficiency.

The risk-return frontier shown in Figure 3 illustrates efficiency when managers choose production plans that do not maximize return. The allocatively efficient plan maximizes return at point $\mathrm{K}$. The production plan that results in the risk-return combination at point $\mathrm{A}$ is less profitable and, thus, is either allocatively or technically inefficient or both. The plan that yields point B is also inefficient by reference to point $\mathrm{K}$; however, it is efficient in the sense that it achieves the maximum feasible return at the level of risk, OC.

\section{V.A. Return and Risk Efficiency}

If the measure of efficiency is amended to allow managers to trade return for reduced risk, it can be gauged as a distance from the frontier at points other than the maximum return. We measure efficiency in four different ways. Following Hughes and Moon (1995), return and risk efficiency are measured along the shortest ray from point $\mathrm{A}$ to point $\mathrm{F}$ on the frontier, the orthogonal ray. Orthogonal return efficiency is then the ratio $1-(\mathrm{HD} / \mathrm{OH})$ while orthogonal risk efficiency is the ratio 1 - (CG/OG). Alternatively, the orthogonal distance to the frontier from point A can be used to measure efficiency and equals $\left[(\mathrm{OH}-\mathrm{OD})^{2}+(\mathrm{OC}-\mathrm{OG})^{2}\right]^{0.5}$. Our fourth efficiency measure uses the one-sided error term from the frontier estimation to separate the bank's luck of the draw from its inherent inefficiency: vertical return efficiency is given by:

$$
1-\frac{E\left(u_{i} \mid \varepsilon_{i}\right)}{\Gamma_{0}+\Gamma_{1} R K_{i}^{\prime}+\Gamma_{2} R K_{i}^{\prime 2}}
$$

where

$$
E\left(u_{i} \mid \varepsilon_{i}\right)=\left(\frac{\sigma_{u} \sigma_{v}}{\sigma}\right)\left[\frac{\varphi\left(\frac{\varepsilon_{i} \lambda}{\sigma}\right)}{\Phi\left(-\frac{\varepsilon_{i} \lambda}{\sigma}\right)}-\frac{\varepsilon_{i} \lambda}{\sigma}\right]
$$


denotes the conditional expectation of $\mathrm{u}_{\mathrm{i}}$ given $\varepsilon_{\mathrm{i}}$ (Jondrow, Lovell, Materov, and Schmidt (1982)).

\section{The Data}

To estimate the impact of geographic diversification on return and risk-taking, we examine BHC data taken from the FRY-9 Financial Statements for all four quarters of 1994. (The data on the number of branches are from Summary of Deposits reports.) We exclude BHCs located in unit banking states, BHCs that consisted primarily of nonbank banks, or special purpose banks. De novos are excluded and are defined as BHCs that were not operating as of June 1986. The final sample includes a total of 443 BHCs, ranging in size from $\$ 32.5$ million to $\$ 249.7$ billion in consolidated assets. ${ }^{8}$

For our production model, we specify the quantity and prices for five outputs (y variables) and five inputs ( $\mathbf{x}$ variables), the level of financial capital (k), nonperforming assets (n), and noninterest income (m). The variables are measured as averages over the four quarters of 1994.

Our output measures are liquid assets $\left(\mathrm{y}_{1}\right)$, short-term securities $\left(\mathrm{y}_{2}\right)$, long-term securities $\left(\mathrm{y}_{3}\right)$, loans and leases net of unearned income $\left(\mathrm{y}_{4}\right)$, and other assets $\left(\mathrm{y}_{5}\right)$. The price or yield of the $\mathrm{i}^{\text {th }}$ output is measured by the ratio of total income from the $\mathrm{i}^{\text {th }}$ asset divided by the quantity of that asset that is accruing interest. This is a measure of the contractual interest rate rather than the ex-post realized interest rate, which will depend on the level of ex-post defaults.

Our input measures are financial capital $(\mathrm{k})$, labor $\left(\mathrm{x}_{1}\right)$, physical capital $\left(\mathrm{x}_{2}\right)$, insured deposits $\left(\mathrm{x}_{3}\right)$, uninsured deposits $\left(\mathrm{x}_{4}\right)$ and other borrowed money $\left(\mathrm{x}_{5}\right)$ and the model also includes the associated input prices $\left(\mathrm{w}_{1}, \ldots, \mathrm{w}_{5}\right)$.

A unique feature of this production model, which was first discussed in HLMM (1995), is its treatment of output prices as a measure of quality. ${ }^{9}$ The differential between the contractual rate of interest and the risk-free rate indicates the average premium incurred by the output and therefore is an indicator of the average quality of the asset. The weighted-average output price is defined as $\tilde{p}=\sum_{i} p_{i}\left[\frac{y_{i}}{\sum_{j} y_{j}}\right]$. 
The estimated model also uses the amount of nonperforming assets, n, as an additional indicator of a BHC's financial condition. Nonperforming assets are measured as the sum of loans, leases, and other assets past due 90 days or more and still accruing interest plus nonaccruing loans, leases, and other assets. $^{10}$

Actual profits depend on the random realization of a stochastic process, and the ex-post realization of profit may not be an accurate indicator of the ex-ante distribution of returns that motivated the production plan. Since actual or realized profit may be quite different from the expected profit that motivated the production plan $(\mathbf{y}, \mathbf{x}, \mathrm{k})$, instead of using actual earnings, we use potential revenue as a proxy for expected revenue. Potential revenue is the revenue that would be earned if all assets accrued interest.

Potential revenue is the sum, $\mathbf{p} \cdot \mathbf{y}+\mathrm{m}$, since $\mathbf{y}$ includes all assets, accruing and nonaccruing, while $\mathbf{p}$ measures the contractual interest rate. Potential accounting profit is $\mathbf{p} \cdot \mathbf{y}+\mathrm{m}-\mathbf{w} \cdot \mathbf{x}$.

Since the federal tax rates are similar for all the BHCs in the data set, the main variations in tax rates come from the state tax component of $\mathrm{p}_{\pi}$. The state tax rates are obtained for each state from The Book of the States, published by the Council of State Governments, and from Significant Aspects of Fiscal Federalism, published by the U.S. Advisory Commission on Intergovernmental Relations.

\section{The Empirical Findings}

The estimation of the structural model of production, equations (7), (8), and (10), yields measures of expected profit and the standard error of expected profit, conditioned on the level of equity capital. ${ }^{11}$ Dividing both terms by equity capital, we obtain for each BHC its expected rate of return on equity and risk, and estimate a best practice frontier, which is shown in Figure 4. ${ }^{12}$

The effects of geographic diversification on expected return, risk, efficiency, and bank safety are investigated by regressing these performance measures on variables that characterize the degree of geographic diversification. The inverse $\mathrm{z}$-score: ${ }^{13}$ 


$$
1 / z=\frac{S\left(p_{\pi} \pi\right)}{\left[k+E\left(p_{\pi} \pi\right)\right]}=\frac{S\left(p_{\pi} \pi\right) / k}{[1+E R]}=\frac{R K}{1+E R}
$$

measures the probability of insolvency, which is inversely related to bank safety.

\section{VII.A. Geographic Diversification, Performance, and Safety}

We characterize a BHC's geographic diversity in several ways. We focus on the BHC's number of branches and the number of states in which it operates. First, controlling for asset size and the number of states, we examine the effect on performance and safety of the number of branches. Second, controlling for asset size and the number of branches, we consider how the number of states in which the BHC operates affects performance and safety. Third, we consider how size, given the number of states and branches, affects performance. Fourth, we ask how a proportional variation in both the number of states and branches, given asset size, affects performance. Last, we consider a proportional variation in the number of states and branches and in asset size.

Each of these variations can be expected to improve diversification. As discussed in section I, their effects on the risk-return frontier depend on whether banks are efficient or inefficient. Enhanced diversification shifts the bank's risk-return frontier upward at all positive levels of risk for inefficient BHCs. Enhanced diversification could change the position of the BHC on the envelope efficient frontier.

In addition to the geographic variables (i.e., the number of states and branches and the amount of total assets), the change in total assets from the last quarter of 1993 to the last quarter of 1994 is included to control for the effects of the growth rate. A dummy variable distinguishing one-bank holding companies is also included. The results of these regressions are reported in Tables 1 and 2.

As shown in Table 1, when the number of branches is varied, holding constant size and the number of states, there is evidence that efficiency is improved. The effects on both orthogonal measures and the vertical return measure of efficiency are significantly positive for the inefficient group. An 
increase in branches has a significant negative effect on risk and an insignificant effect on expected return. Thus, for the inefficient, a wider branching network reduces risk, reduces its orthogonal distance from the frontier, and improves efficiency. For the efficient, both risk and expected return are significantly reduced by an increase in branching. (In fact, branching is the only variable that significantly affects return, risk, or bank safety for efficient BHCs.) These two effects suggest that more extensive branching moves the efficient BHC down the envelope toward lower return and risk. Consistent with this interpretation, the inverse z-score is significantly reduced for efficient banks with more branches.

When the number of states is expanded, holding constant the amount of total assets and the number of branches, the risk of inefficient BHCs is significantly increased, with an almost significant positive effect on expected return. There is no significant impact on any of our four measures of efficiency. Insolvency risk, as measured by the inverse z-score, increases as the number of states increases. On the other hand, an expansion in the number of states does not have a significant impact on the expected return, risk, or insolvency risk of efficient BHCs, although the signs are opposite to those of an increase in branches.

When total assets are increased, holding constant the number of states and branches, there is no significant effect on the efficient banks while, for the inefficient, risk is significantly increased, efficiency by all four measures is significantly reduced, and bank safety is significantly diminished.

A BHC that is geographically diversifying might be expected to increase both branches and number of states. Thus, we investigate the effect when the number of states and branches is increased proportionately, holding the asset size of the BHC constant. (Holding the asset size constant focuses on the effect of diversification as distinct from the effect of a change in size.) Tables 1 and 2 report the average value of this derivative for the inefficient and efficient BHC subsamples, respectively. We find that, on average, the expected return of inefficient BHCs is significantly increased by the proportionate increase, risk is insignificantly increased, both orthogonal efficiency measures and the vertical return 
efficiency are significantly improved, and the inverse z-score is insignificantly increased. On average, there is no significant effect on expected return, risk, or bank safety for efficient BHCs. This suggests that once restrictions on geographic diversity are relaxed we would not expect to see efficient BHCs located at any specific region on the envelope frontier but rather scattered over the envelope.

Finally, we also investigated the effect of a proportionate increase in branches, states, and assets. On average, for inefficient BHCs, the effect on expected return is still significantly positive, but the effect on risk becomes significantly positive, reflecting the effect of asset growth on risk. These two effects counterbalance each other so there is no longer a significant effect on efficiency. The expansion now implies, on average, a significant increase in an inefficient BHC's inverse z-score, i.e., a decrease in bank safety. On average, for efficient BHCs, the expansion still has an insignificant effect on expected return, risk, and bank safety.

A number of studies have considered how geographic expansion affects the return and risk of these BHCs. Although there are substantial differences in measures and methods, Rose (1995) ends his survey of these studies by concluding that most of them find little evidence that geographic expansion improves profitability or reduces risk. In fact, risk is often found to increase. Chong (1991) uses stock market returns and the event-study methodology and finds that interstate expansion increases profitability and risk. Chong concluded that, while geographic expansion reduces the risk of a given portfolio, it also expands the bank's opportunities to take risks. A similar conclusion is reached by Demsetz and Strahan (1995), who examine stock market data and find that, when they control for the bank's portfolio composition and activities, improved diversification reduces risk. When they allow banks to adjust to improved diversification, risk is no longer necessarily reduced. Preliminary findings of Akhavein, Berger, and Humphrey (1995) demonstrate that large bank mergers significantly improve profit efficiency and that this improvement seems to result from increases in loan-to-asset ratios and increases in banks' leverage. They conclude that the larger scale of these merged banks and their greater geographic diversity allow them to increase their loan-to-asset ratios and leverage without increasing 
risk.

\section{Conclusions and Policy Implications}

Methods and measures differ between this study and those cited, but the complex intuitions and conclusions are remarkably similar. The evidence does not reject the simple intuition that better geographic diversification leads to improved profitability, reduced risk, and enhanced bank safety. Instead, the evidence qualifies this often stated presumption. And the qualifications are important. The simple intuition implicitly assumes that risk is exogenous. The analytical device of managerial utility and the characterization of production plans in terms of their implied return and risk make evident the essential endogeneity of risk. Highlighting the differences between efficient and inefficient banks, it also clarifies the effects on production of improved diversification and demonstrates that there is not an ex ante predictable relationship between endogenous risk and diversification. With intuition sharpened, the focus can turn to the important implications of geographic diversification for bank safety.

Our results indicate that improved opportunities for geographic expansion will yield increased average returns and increased efficiency in the banking system, since a proportional increase in branches and states yielded significantly positive effects on expected returns and efficiency of the inefficient BHCs in our sample, which make up more than $88 \%$ of our sample. Our estimates indicate that geographic expansion (holding asset size constant) does not have a significant impact on insolvency risk for the BHCs in our sample.

What do these results mean for the safety of the banking system as a whole, the aggregate number of bank failures, and the aggregate expected losses from bank failures? We calculated the weighted aggregate effect on the inverse z-scores across our sample of a proportionate increase in the number of states and branches, holding assets constant, where each BHC's weight is its share of assets. (Recall that the estimates reported at the bottom of Tables 1 and 2 are the average effect of a

proportionate increase.) This weighted aggregate effect is -0.001680 (with standard error 0.0006734 and 
t-statistic -2.495); i.e., an increase in expansion implies a decrease in insolvency risk. This is consistent with the view that increased geographic expansion is likely to improve aggregate bank safety. However, this statistic alone is not sufficient to determine the direction of expected insolvencies and expected losses for the banking system as a whole. Determining the direction and magnitude of these aggregate effects will be a subject of future research. 


\section{REFERENCES}

Akhavein, Jalal D., Allen N. Berger, and David Humphrey. "The Effects of Megamergers on Efficiency and Prices: Evidence from a Bank Profit Function," manuscript, Board of Governors of the Federal Reserve System, December 1995.

Berger, Allen N., and Robert DeYoung. "Problem Loans and Cost Efficiency in Commercial Banks," manuscript, Board of Governors of the Federal Reserve System, October 1995.

Blair, Roger D., and Arnold A. Heggestad. "Bank Portfolio Regulation and the Probability of Failure," Journal of Money, Credit, and Banking 10 (1978), 88-93.

Chong, Beng Soon. "The Effects of Interstate Banking on Commercial Banks' Risk and Profitability," Review of Economics and Statistics (1991), 78-84.

Demsetz, Rebecca S., and Philip E. Strahan. "Diversification, Size, and Risk at Bank Holding Companies,” Federal Reserve Bank of New York, Research Paper \#9506, April 1995.

Hancock, Diana. "The Financial Firm: Production with Monetary and Nonmonetary Goods," Journal of Political Economy 93 (1985), 859-80.

Hancock, Diana. “A Model of the Financial Firm with Imperfect Asset and Deposit Liabilities," Journal of Banking and Finance 10 (1986), 37-54.

Hughes, Joseph P., William Lang, Loretta J. Mester, and Choon-Geol Moon. "Recovering Technologies that Account for Generalized Managerial Preferences: An Application to Non-Risk-Neutral Banks,” Working Paper No. 95-8/R, Federal Reserve Bank of Philadelphia, September 1995.

Hughes, Joseph P. and Choon-Geol Moon. "Measuring Bank Efficiency When Managers Trade Return for Reduced Risk,” Working Paper, Department of Economics, Rutgers University, September 1995.

Hughes, Joseph P., William Lang, Loretta J. Mester, and Choon-Geol Moon. "Efficient Banking Under Interstate Branching," Journal of Money, Credit, and Banking (forthcoming).

Hughes, Joseph P., and Loretta J. Mester. “A Quality and Risk-Adjusted Cost Function for Banks: 
Evidence on the 'Too-Big-to-Fail' Doctrine," Journal of Productivity Analysis 4 (1993), 292-315.

Hughes, Joseph P., and Loretta J. Mester. "Bank Capitalization and Cost: Evidence of Scale Economies in Risk Management and Signaling," Working Paper No. 96-2, Federal Reserve Bank of Philadelphia, December 1995.

Jondrow, J., C.A.K. Lovell, I.S. Materov, and P. Schmidt. "On the Estimation of Technical Inefficiency in the Stochastic Frontier Production Function Model," Journal of Econometrics 19 (1982), 233238.

Koehn, Michael, and Anthony M. Santomero. "Regulation of Bank Capital and Portfolio Risk," Journal of Finance 35 (1980), 1235-1247.

McAllister, Patrick H., and Douglas McManus. "Resolving the Scale Efficiency Puzzle in Banking," Journal of Banking and Finance 17 (1993), 389-406.

Mester, Loretta J. "How Efficient Are Third District Banks?" Business Review, Federal Reserve Bank of Philadelphia (January/February 1994), 3-18.

Rose, Peter S. "Diversification and Interstate Banking," manuscript, Texas A\&M University Graduate School of Business, March 1995. 
FIGURE 1. Shifting Risk-Return Frontier

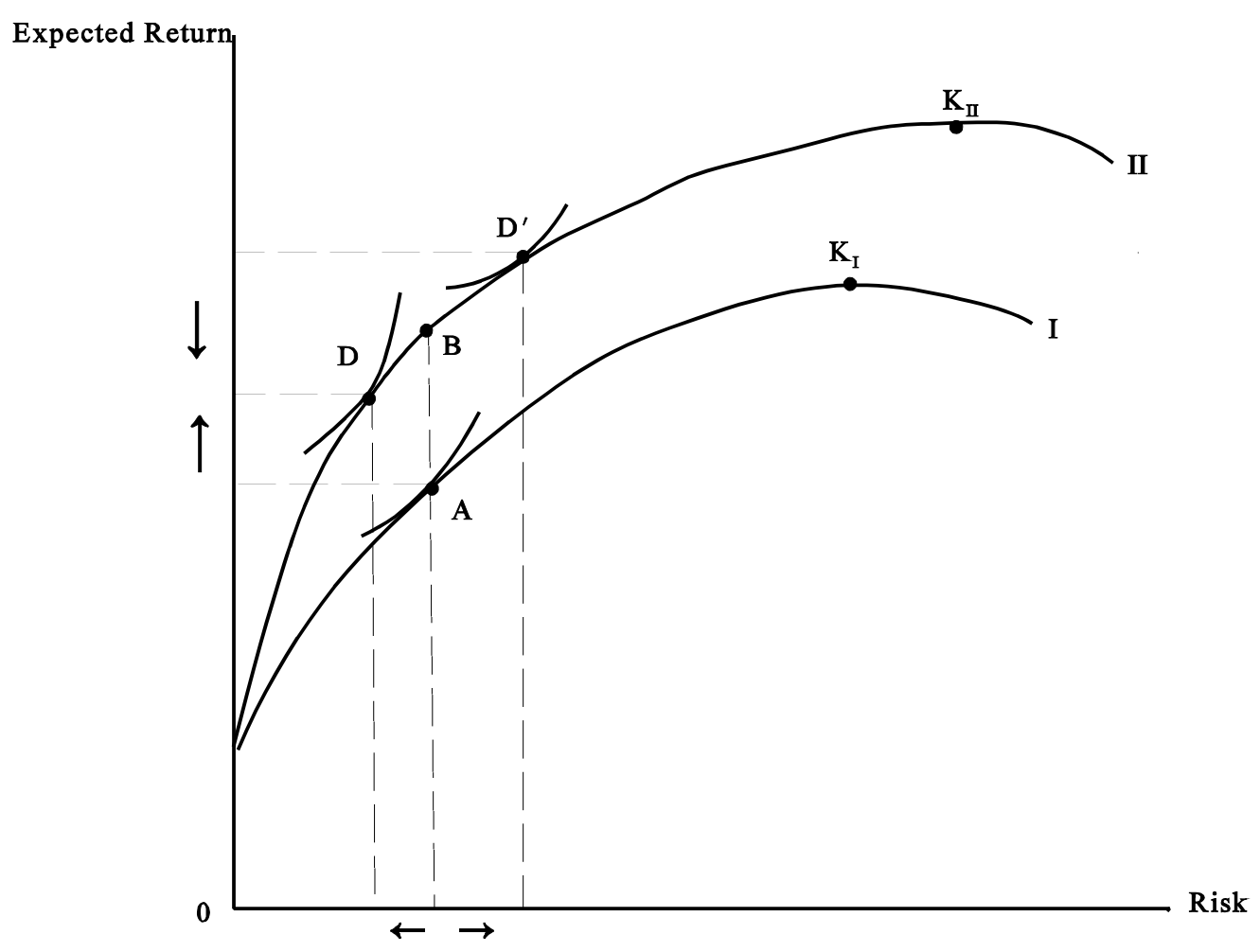


FIGURE 2. Iso-1/z Contour

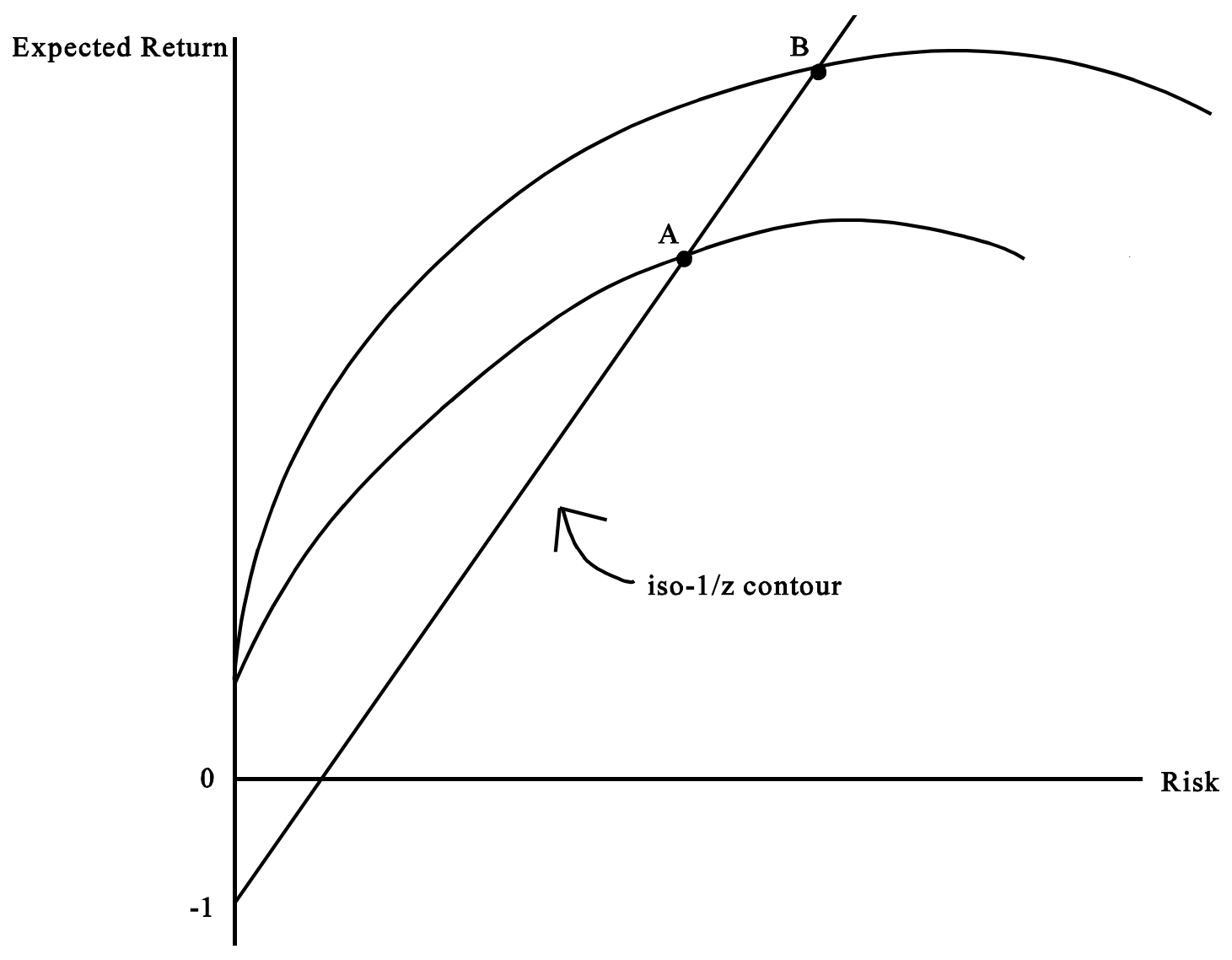


FIGURE 3. Risk-Return Frontier Conditional on Equity Capital

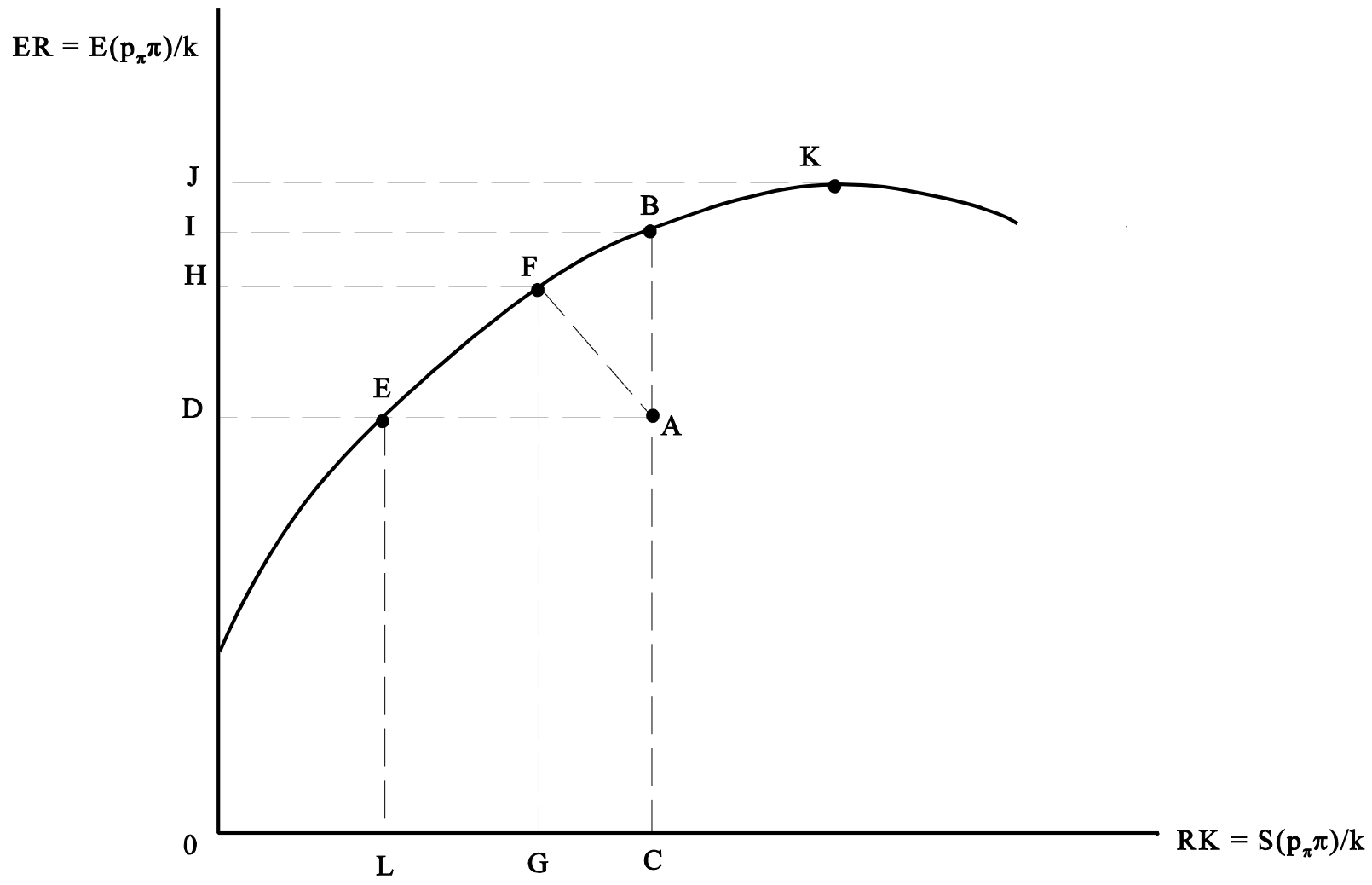


FIGURE 4. Risk-Return Frontier of U.S. BHCs, 1994 Data

\section{Expected Return}

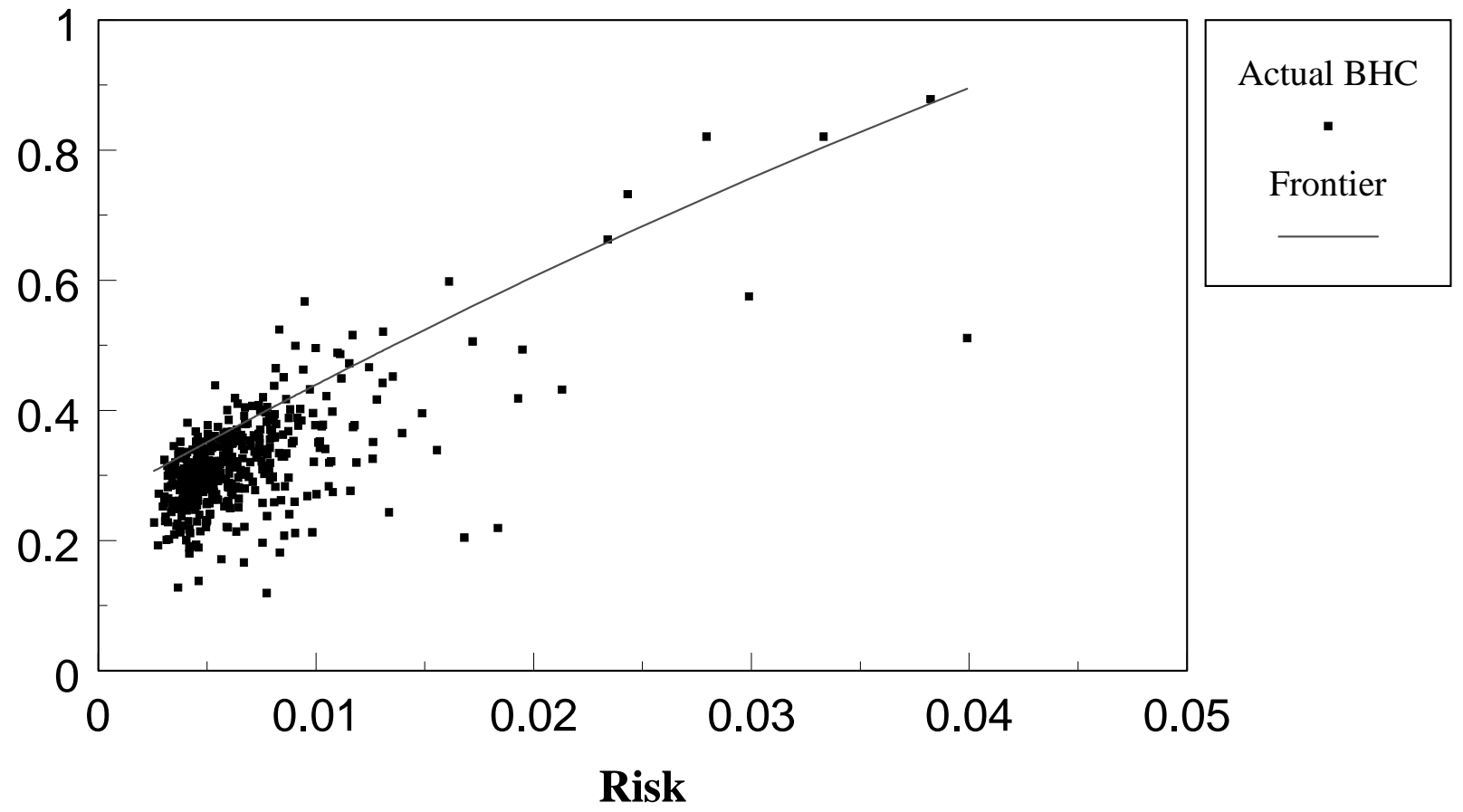


TABLE $1^{1}$

\section{INEFFICIENT BHCs}

\begin{tabular}{|c|c|c|c|c|c|c|c|c|}
\hline Dependent Variable & Inverse $\mathrm{z}$ - & core & Expected F & turn & Risk & & $\mathbf{E}(\mathbf{u} \mid \mathbf{v - \mathbf { l }}$ & \\
\hline & Coefficient & t-stat & Coefficient & t-stat & Coefficient & t-stat & Coefficient & t-stat \\
\hline Constant & $.435576 \mathrm{E}-02$ & 18.6569 & .291393 & 46.1372 & $.562768 \mathrm{E}-02$ & 16.2550 & .822659 & 95.6417 \\
\hline One Bank Holding Co. & $.480097 \mathrm{E}-03$ & 1.99447 & $.325154 \mathrm{E}-02$ & .499326 & $.675250 \mathrm{E}-03$ & 1.89167 & -.010326 & -1.16436 \\
\hline Number of States & $.332819 E-03$ & 2.95625 & $.497540 \mathrm{E}-02$ & 1.63364 & $.502516 \mathrm{E}-03$ & 3.00999 & $-.174340 \mathrm{E}-02$ & -.420322 \\
\hline Number of Branches & $-.619865 \mathrm{E}-05$ & -5.95559 & $-.695687 \mathrm{E}-06$ & -.024708 & $-.848772 E-05$ & -5.49921 & $.164804 \mathrm{E}-03$ & 4.29780 \\
\hline Change in Assets & $-.161384 \mathrm{E}-02$ & -1.90700 & .029210 & 1.27591 & $-.201803 \mathrm{E}-02$ & -1.60805 & .097994 & 3.14300 \\
\hline Total Assets & $.487565 \mathrm{E}-10$ & 8.00437 & $-.200486 \mathrm{E}-09$ & -1.21668 & $.628485 \mathrm{E}-10$ & 6.95779 & $-.153409 \mathrm{E}-08$ & -6.83592 \\
\hline Sample Size & 391 & & 391 & & 391 & & 391 & \\
\hline R-squared & 0.183 & & 0.019 & & 0.151 & & 0.139 & \\
\hline $\begin{array}{l}\text { Proportional Geographic } \\
\text { Expansion /Holding Size Constant }{ }^{2}\end{array}$ & $.935320 \mathrm{E}-04$ & .613013 & .867419E-02 & 2.10152 & $.210167 \mathrm{E}-03$ & .928872 & .997928E-02 & 1.77525 \\
\hline $\begin{array}{l}\text { Proportional Geographic } \\
\text { Expansion /Allowing Size To Vary }\end{array}$ & $.448066 \mathrm{E}-03$ & 3.19310 & $.721635 \mathrm{E}-02$ & 1.90101 & $.667171 \mathrm{E}-03$ & 3.20619 & $-.117588 \mathrm{E}-02$ & -.227449 \\
\hline
\end{tabular}

${ }^{1}$ Bold numbers indicate significance at the $10 \%$ level or better.

${ }^{2}$ The proportional geographic expansion results are derived estimates from the estimated regression above. 
TABLE 1, con't.

\section{INEFFICIENT BHCS}

\begin{tabular}{|c|c|c|c|c|c|c|}
\hline \multirow[t]{2}{*}{ Dependent Variable } & \multicolumn{2}{|c|}{$\begin{array}{c}\text { Orthogonal Risk } \\
\text { Efficiency }\end{array}$} & \multicolumn{2}{|c|}{$\begin{array}{c}\text { Orthogonal Return } \\
\text { Efficiency }\end{array}$} & \multicolumn{2}{|c|}{$\begin{array}{c}\text { Orthogonal Distance to } \\
\text { the Frontier }\end{array}$} \\
\hline & Coefficient & t-stat & Coefficient & t-stat & Coefficient & t-stat \\
\hline Constant & .49349 & 14.872 & .87032 & 105.469 & .633494 & 13.0083 \\
\hline One Bank Holding Co. & -.027298 & -.649 & -.012886 & -1.268 & .078580 & 1.56501 \\
\hline Number of States & $.75929 \mathrm{E}-02$ & .553 & $-.22740 \mathrm{E}-02$ & -.693 & .032499 & 1.38390 \\
\hline Number of Branches & $.37075 E-03$ & 1.807 & $.18970 \mathrm{E}-03$ & 3.301 & $-.1305 \mathrm{E}-02$ & -6.00976 \\
\hline Change in Assets & .39488 & 2.064 & .11359 & 2.968 & -.579151 & -3.28086 \\
\hline Total Assets & $-.354301 E-08$ & -2.072 & $-.171384 \mathrm{E}-08$ & -3.046 & $.1156362 \mathrm{E}-07$ & 9.10105 \\
\hline Sample Size & 391 & & 391 & & 391 & \\
\hline R-squared & 0.051 & & 0.131 & & 0.219 & \\
\hline $\begin{array}{l}\text { Proportional Geographic } \\
\text { Expansion /Holding Size Constant }\end{array}$ & .042653 & 2.5112 & .011018 & 2.2322 & -.046203 & -1.4517 \\
\hline \begin{tabular}{|l|} 
Proportional Geographic \\
Expansion /Allowing Size To Vary
\end{tabular} & .016890 & 1.0476 & $-.14445 \mathrm{E}-02$ & -0.3422 & .037882 & 1.2942 \\
\hline
\end{tabular}


TABLE $2^{3}$

\section{EFFICIENT BHCs}

\begin{tabular}{|c|c|c|c|c|c|c|}
\hline \multirow[t]{2}{*}{ Dependent Variable } & \multicolumn{2}{|c|}{ Inverse z-score } & \multicolumn{2}{|c|}{ Expected Return } & \multicolumn{2}{|l|}{ Risk } \\
\hline & Coefficient & t-stat & Coefficient & t-stat & Coefficient & t-stat \\
\hline Constant & $.671145 \mathrm{E}-02$ & 4.24940 & .468081 & 9.19903 & .010469 & 3.50203 \\
\hline One Bank Holding Co. & $-.405978 \mathrm{E}-03$ & -.327210 & $.778512 \mathrm{E}-03$ & .019476 & $-.853354 \mathrm{E}-03$ & -.363383 \\
\hline Number of States & $.727780 \mathrm{E}-03$ & .781791 & .028937 & .964838 & $.165277 \mathrm{E}-02$ & .938024 \\
\hline Number of Branches & $-.355208 E-04$ & -1.99471 & $-.129767 \mathrm{E}-02$ & -2.26188 & $-.660546 \mathrm{E}-04$ & -1.95980 \\
\hline Change in Assets & $-.472730 \mathrm{E}-02$ & -1.17469 & -.162322 & -1.25198 & $-.998295 \mathrm{E}-02$ & -1.31063 \\
\hline Total Assets & $.191921 \mathrm{E}-09$ & .572918 & $.625030 \mathrm{E}-08$ & .579136 & $.271157 \mathrm{E}-09$ & .427662 \\
\hline Sample Size & 52 & & 52 & & 52 & \\
\hline R-squared & 0.156 & & 0.199 & & 0.164 & \\
\hline $\begin{array}{l}\text { Proportional Geographic } \\
\text { Expansion /Holding Size Constant }{ }^{4}\end{array}$ & $-.599741 \mathrm{E}-03$ & -.276450 & -.017934 & -.256595 & $-.608624 \mathrm{E}-03$ & -.148222 \\
\hline $\begin{array}{l}\text { Proportional Geographic } \\
\text { Expansion /Allowing Size To Vary }\end{array}$ & $-.7720 \mathrm{E}-05$ & $-.653770 \mathrm{E}-02$ & $.134602 \mathrm{E}-02$ & .035379 & $.227815 \mathrm{E}-03$ & .101924 \\
\hline
\end{tabular}

${ }^{3}$ Bold numbers indicate significance at the $10 \%$ level or better.

${ }^{4}$ The proportional geographic expansion results are derived estimates from the estimated regression above. 


\section{NOTES}

1. See Rose (1995) for a summary of these studies.

2. In this paper the term bank safety refers to the risk of insolvency, while risk means the riskiness of bank returns.

3. See HLMM (forthcoming) for a more complete discussion of this methodology.

4. Given a risk-free asset, the concavity of the risk-return frontier will occur if the cost of funds is sensitive to the bank's level of risk.

5. This assumes that there are efficient BHCs that are not geographically diversified, which is true in our sample.

6. A similar procedure was used by Blair and Heggestad (1978) to analyze the effects of portfolio regulation on bank safety. See also Koehn and Santomero (1980). The inverse z-score is an exact measure of the probability of insolvency when profits are normally distributed.

7. A sufficient condition for this result is that the frontier be non-convex.

8. This data set is identical to the one used in HLMM (forthcoming). See that paper for a complete definition of the variables used in estimating the production model. A summary of the data is available from the authors.

9. Note that the endogeneity of prices is not here an indication of market power. It is assumed that there is an exogenous market price for outputs of a given quality.

10. Berger and DeYoung (1995) discuss the various relationships between problem loans and bank efficiency.

11. A Wald test of the conditions for risk neutrality has a p-value close to zero. Hence, risk neutrality is rejected.

12. This graph is identical to Figure 1 in HLMM (1995). The parameter estimates for the production model and the efficient frontier are available from the authors.

13. There is a difference between the insolvency risk of a BHC and that of the individual subsidiaries. However, several factors tie the two together. The "cross guarantee" provisions of FIRREA (1989) 
make commonly controlled depository institutions liable for any losses. In addition, BHCs can borrow to supply capital to their bank subsidiaries. 